\title{
Colonisation and extinction in relation to competition and resource partitioning in acanthocephalans of freshwater fishes of the British Isles
}

\author{
Alastair R. Lyndon ${ }^{1,2}$ and Clive R. Kennedy ${ }^{1}$ \\ ${ }^{1}$ Department of Biological Sciences, Hatherly Laboratories, University of Exeter, Exeter, EX4 4PS, UK; \\ ${ }^{2}$ Department of Biological Sciences, Heriot-Watt University, Edinburgh, EH14 4AS, UK
}

Key words: Acanthocephala, colonisation, extinction, fish, persistence, resource partitioning

\begin{abstract}
This paper challenges two paradigms long held in relation to the ecology of parasites in freshwater systems: (1) autogenic species are poorer colonisers than allogenic ones; and (2) parasites with direct life cycles are more successful colonisers than those with complex life cycles. Using new and existing data for Acanthocephala in freshwater fish from the British Isles, it is suggested that all six species present have been able to colonise and persist successfully, in spite of the supposed limitations of their autogenic life-style. It is proposed that these parasites have overcome these limitations by a variety of means, which apply equally to all species considered. Foremost among these is the utilisation of a migratory fish host as either a preferred or a suitable host in their life cycle, allowing colonisation of new areas and rescue effects in established areas, whilst equally important is the use of a common and widespread crustacean as the intermediate host. In addition, all six species appear to exhibit resource partitioning by host at either or both the larval and adult stages, thus reducing the potential for competition and further facilitating colonisation and survival. This hypothesis is supported by data from previous studies both on acanthocephalans from Europe and North America and on other autogenic parasites. It also provides an explanation for the apparently atypical host utilisation patterns of some acanthocephalan species in areas on the edge of their distributions, notably in Ireland.
\end{abstract}

All parasites, like free-living organisms, need to disperse and colonise new localities (Kennedy 1975). They then need to survive in a locality after colonisation, through periods of unfavourable conditions and in the face of potential competitors. These two requirements, to pioneer and to perpetuate, are generally considered independently of each other; almost as alternative strategies in relation to colonisation and extinction respectively (Kennedy 1985). However, a colonisation event and an extinction event may be indistinguishable at the moment they are observed: they are essentially two sides of the same coin. The same strategy is required for a population to establish from a colonising propagule as for a population to recover from the brink of extinction.

In the context of colonisation, there are two widely accepted paradigms. In respect of parasites in freshwater systems, it is believed that allogenic species are better colonisers than autogenic species, since the former can use their more mobile definitive hosts to cross land barriers between catchments and so reach and invade new localities (Esch et al. 1988). The second paradigm is that parasites with direct life cycles will be more successful colonists than those with indirect life cycles, since the latter require the presence of more species at appropriate densities in a locality to provide intermediate host(s) and create a resource patch in space and time (Price 1980). The probability of colonisation suc- cess can further be improved, and the probability of local extinction reduced, if there is, in addition, a resting stage in either type of life cycle and/or the threshold abundance for population survival is very low (Kennedy 1994). These two paradigms are, of course, to a large extent contradictory since allogenic species, by definition, have indirect life cycles. Nevertheless, on the basis of these paradigms, and despite this contradiction, it could be predicted that autogenic species with indirect life cycles would be poorer colonisers and more vulnerable to local extinctions than either allogenic species or species with direct life cycles.

The history of fish parasite introductions to the British Isles suggests, however, that this prediction is incorrect, as the most successful invaders have been autogenic species with at least one intermediate host in their life cycle (Kennedy 1994). The prediction would also appear to be incorrect in respect of the acanthocephalan parasites of freshwater fish of the British Isles. These are autogenic and require an arthropod intermediate host, yet they are widely distributed throughout the British Isles, they can persist at low population levels in some localities and they can also colonise new localities very readily (Kennedy 1993, 1996, 1997, Kennedy et al. 1989). The aim of the present paper is thus to challenge the stated paradigms, and the predictions consequent upon them, by a re-evaluation and interpretation of the distributions and host 
utilisation by the six acanthocephalan species using freshwater fish as their definitive hosts in the British Isles. We will endeavour to explain why, contrary to prediction and apparent life cycle limitations, freshwater acanthocephalans are, in fact, very good colonists and survivors, and why inter-specific competition is uncommon (Kennedy 1985, 1992, Kennedy and Moriarty 1987, Bates and Kennedy 1990, 1991) and seldom plays a role in colonisation or extinction. Ultimately, we provide a single, integrated interpretation of colonisation and survival strategies, inter-specific competition and resource partitioning amongst acanthocephalans of freshwater fish in the British Isles and test this by reference to data from Continental Europe and North America.

\section{MATERIALS AND METHODS}

Most of the information on acanthocephalan distribution and host utilisation is taken from published records, including Kennedy (1974), Brown et al. (1986) and Holland and Kennedy (1997). This information has been supplemented by the results of our own (unpublished) surveys and by reference to original data sets for published accounts (Kennedy 1990, 1993, 1997), as well as original data on wet (filter paper blotted) weights of individual acanthocephalans from a variety of hosts and localities. Fish were caught by a variety of methods and examined for acanthocephalan infections by standard procedures (e.g. Lyndon 1996). Stages of female acanthocephalan maturity were recorded according to Bates and Kennedy (1990): immature females are F1 and gravid females containing fully developed, shelled acanthors are F3.

The preferred host species of a particular acanthocephalan species is defined as that in which the parasite matures and reaches maximum size (and, therefore, fecundity) and most females reach F3; a suitable host is one in which the parasite can grow to a smaller adult size but in which many females reach the F3 stage; an additional host is one in which the parasite makes some growth and few females reach F3 stage, but most do not; an accidental host is one in which the parasite makes little or no growth and seldom, if ever, do females reach F3. Thus, both suitable and additional hosts are subdivisions of what are sometimes referred to as auxiliary hosts. A colonisation host is defined as a migratory fish species which can act as either a suitable or preferred host (see above), thus facilitating the movement of reproducing parasites (a colonising propagule) into new localities. Other terminology relating to parasite population and community parameters follows that suggested by Bush et al. (1997).

In this account Ireland refers to the whole of Ireland, regardless of national divisions: Britain to England, Wales and Scotland: and the British Isles to the geographical unit encompassing Britain and Ireland.

\section{RESULTS}

\section{Distribution}

It is now accepted (Brown et al. 1986) that only six species of Acanthocephala have been found as adults in the intestines of freshwater fish in the British Isles. All six are also found in continental Europe, but only one, Neoechinorhynchus rutili (Müller, 1780), also occurs in North America. The remaining five species are thus at the edges of their Palaearctic distributional ranges in the British Isles. All six species colonised the British Isles in the post-glacial period (see Varley 1967, Wheeler 1977 and Kennedy et al. 1989 for full discussion of post-glacial colonisation events in relation to freshwater fish and their parasites) and are widespread through Britain and Ireland (Kennedy 1974, Kennedy et al. 1989, Holland and Kennedy 1997), although some local patterns of distribution are still detectable in relation to post-glacial colonisation routes and subsequent anthropochore fish stockings (Kennedy et al. 1989). None of the species is rare over the British Isles as a whole, but any may be rare locally.

\section{Specificity}

Reference to checklists (Kennedy 1974, Holland and Kennedy 1997) suggests that these acanthocephalans show very little specificity to their definitive, as opposed to intermediate, hosts. This view was challenged by Chubb (1967) and does not accord with the data presented in Tables 1 and 2. Using adult female size as a criterion (Table 1), a preferred definitive host can clearly be recognised for the three species of Acanthocephalus, namely Acanthocephalus anguillae (Müller, 1780), Acanthocephalus clavula (Dujardin, 1845), Acanthocephalus lucii (Müller, 1780) and for Pomphorhynchus laevis (Müller, 1776). The situation is less clear-cut for Echinorhynchus truttae (Schrank, 1788), while comparable size data do not exist for $N$. rutili. Table 1 does not include data from all the species of fish from which the parasite has been recorded, but only from species selected as examples (see later for justification). When size data are combined with published information on maturity status of the parasite species in each host (Table 2), it is possible to recognise preferred hosts for each species and identify the status of migratory fish [eel, Anguilla anguilla (L.) and brown trout, Salmo trutta L.] as hosts for each of them.

When information on intermediate host preference and utilisation is also incorporated, it is possible to construct a matrix of life cycles and host utilisation (Fig. 1). There is evidently some overlap in the utilisation of both definitive and intermediate hosts by species of acanthocephalan. For instance, both $N$. rutili and $E$. truttae use brown trout as a preferred definitive host in Britain, while both $A$. anguillae and $P$. laevis use chub as a preferred definitive host, also in Britain. Similarly, both $A$. anguillae and A. lucii use Asellus aquaticus (L.) as their intermediate host, while $P$. laevis and E. truttae each utilise Gammarus pulex (L.) for this purpose. Furthermore, the use of hosts may change between Britain and Ireland: in Ireland, where G. pulex is only a very recent introduction (Gledhill et al. 1993), P. laevis and $E$. truttae infect the common native species $G$. duebeni Liljeborg. Likewise, in the absence of chub 
Table 1. Suitability of definitive hosts for acanthocephalan species as measured by the fresh weight (mg) of gravid (F3) female worms. Data presented as mean \pm SD (maximum). $\mathrm{n}$ - number of worms. B - Britain, I - Ireland. No comparable data are available for weights of either Acanthocephalus anguillae or Pomphorhynchus laevis in barbel.

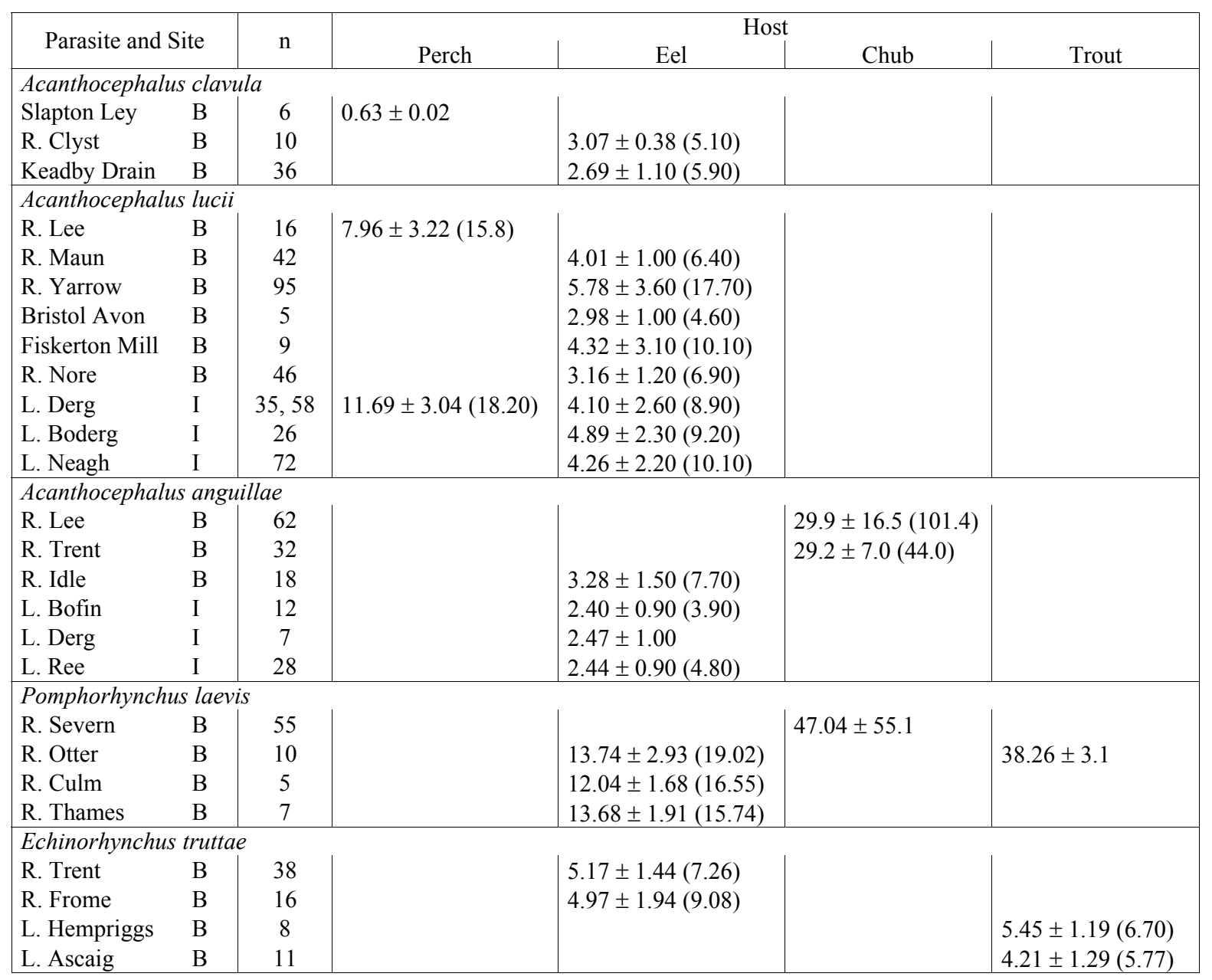

Table 2. Status of migratory fish as definitive hosts for acanthocephalans of British freshwater fish.

\begin{tabular}{|c|c|c|c|}
\hline \multirow{2}{*}{ Acanthocephalan species } & \multirow{2}{*}{ Preferred host } & \multicolumn{2}{|c|}{ Host status/parasite reproduction } \\
\hline & & Eel & Brown trout \\
\hline Neoechinorhynchus rutili & Brown trout & Poor/most F1 & Preferred/F3 \\
\hline Echinorhynchus truttae & Brown trout & Suitable/some F3 & Preferred/F3 \\
\hline Pomphorhynchus laevis & Chub, Barbel & Accident/rare F3 & Suitable/F3 \\
\hline Acanthocephalus clavula & Eel & Preferred/F3 & Suitable/F3 \\
\hline Acanthocephalus lucii & Perch & Suitable/F3 & Suitable/F3 \\
\hline Acanthocephalus anguillae & Chub & Suitable/F3 & Unrecorded \\
\hline
\end{tabular}

from Ireland, $P$. laevis uses trout and $A$. anguillae uses eels as their respective preferred definitive hosts (Kennedy et al. 1989). It would appear that $N$. rutili is unique amongst the six acanthocephalan species considered in its ability to use alternative hosts: it appears to have separate cycles employing either ostracods and three-spined stickleback or Sialis lutaria (L.) and trout (Walkey 1967, Lassiere 1988).
Nevertheless, it is apparent that, in Britain, when species share a preferred definitive host they do not share the same intermediate host. Conversely, when they share the same intermediate host, they have different definitive host preferences (Table 3). This can be interpreted as resource partitioning by host. The only exception to this generalisation occurs in Ireland, where $E$. truttae and P. laevis show the same preference for 
both intermediate and definitive hosts. Two other points can be made from Tables 1-3 and Fig. 1. Firstly, the species used as intermediate hosts are always widespread, frequently encountered in a wide range of freshwater localities and conditions, and often locally abundant: they are amongst the commonest invertebrate species found in European freshwaters. The second point is that every species of acanthocephalan has at least one species of migratory, euryhaline fish amongst its preferred and suitable hosts (Table 2). All six species have been reported from eels, although not every one can attain the F3 stage there, while five species use brown trout as a preferred or suitable host.

\section{Colonisation, extinction and persistence}

In the context of rarity and commonness, "rare" is arbitrarily defined as a mean abundance of 0.05 or less, and "common" as a mean abundance of 5.0 or greater. It is apparent (Tables 4 and 5) that each acanthocephalan species can be rare in eels in one locality and common in another. It is also apparent that colonisation, extinction and persistence at low levels are not uncommon events.

Samples taken from the same locality at irregular intervals indicate extensive temporal changes in species composition and abundance in some localities but not in others (Table 4). In the R. Teifi, N. rutili had disappeared without replacement at some point between 1964 and 1988. In the R. Frome only A. lucii was present in 1987 , but this had disappeared five years later and was replaced by $E$. truttae and $P$. laevis (at the level of rarity). In Shobrooke Lake, A. lucii was present in one year and $A$. clavula in the next, but both species had disappeared without replacement nine years later. By contrast, in the R. Culm, no species was found in 1981, A. lucii was present in 1986, and A. clavula and $P$. laevis (at common level) in 1997. A different, and more stable, situation was seen in the Exminster Marshes (despite the appearance and disappearance of $N$. rutili) and in the Hampshire Avon. Interestingly, despite all of these changes, no species other than $P$. laevis (in the $\mathrm{R}$. Frome) occurred at the level of rarity. On the other hand, a species could be common ( $N$. rutili in the $\mathrm{R}$. Teifi) and yet disappear, or be less common (A. clavula in the Exminster Marshes) and yet persist. Irregular samples such as these indicate change, but reveal little of its direction: they are essentially snapshots in time when what is really required for interpretation is a continuous record.

Examination of long-term, continuous records (Table 5) confirms the impression of instability and change provided by the irregular samples. In the R. Clyst, eels are the only host available for $A$. clavula and $N$. rutili (Kennedy et al. 1992). Acanthocephalus clavula declined to 1983 and then disappeared. Its reappearance thereafter may indicate a rescue effect (Kennedy 1993) or persistence at low, rare levels (in 1987 and 1992). By contrast, $N$. rutili did not appear until 1987 but occurred in all years thereafter, except 1994. This species also persisted at, or close to, the level of rarity in some years. Species composition was even more erratic in the R. Otter, none of the three recorded species ever approaching common status. $P$. laevis was most frequent in trout, having been introduced into the river with this species (Kennedy 1996), and the suprapopulation is maintained by the cycle through trout. For both $A$. clavula and $N$. rutili, however, eels appear to be the only host in this locality, and both species were absent from many samples and rare in others. In Slapton Ley, A. clavula disappeared from perch (Perca fluviatilis L.) after 1980 and never reinfected this host, even when common in eels during 1986. From that year on, its abundance declined and it has not been found at all in 1996 or 1997. Here rarity may have been the prelude to local extinction. Finally, in Lough Derg, A. lucii has always been the dominant species and $A$. anguillae, which appears to use only eels as its host in this locality, has always persisted at low, though not rare, levels of abundance. Both species, but especially A. lucii, appear to have declined over the 14 years of sampling, but no other species has invaded eels.

\section{DISCUSSION}

The data presented here confirm the view of Chubb (1967) that the acanthocephalans of freshwater fish in the British Isles do exhibit specificity towards both definitive and intermediate hosts. The pattern of host preferences revealed in Table 3 is strongly suggestive of resource partitioning by host and this in turn could well have arisen in response to actual or potential interspecific competition in the evolutionary past. It is thus surprising neither that inter-specific competition in contemporary time within fish hosts is both uncommon and somewhat erratic in occurrence (Kennedy and Moriarty 1987, Bates and Kennedy 1990, 1991, Kennedy 1992), nor that site segregation within a fish host is not very precise at the infracommunity level (Kennedy 1985).

Nevertheless, inter-specific competition can take place and it is predicted that it may occur between species that share the same preferred definitive host. Acanthocephalus anguillae and P. laevis are the only cyprinid specialists amongst the acanthocephalans studied, and although they show partitioning in their use of migratory fish, they both prefer chub as a definitive host. Inter-specific competition has, in fact, been demonstrated between these two species, albeit that this was in the laboratory using an introduced, neutral host, Oncorhynchus mykiss (Walbaum) (Bates and Kennedy 1990, 1991). It can be predicted that it may occur between $E$. truttae and $N$. rutili in brown trout, their common preferred definitive host, although this has yet to be demonstrated experimentally: in many localities only one of these two species occurs, and when they do co-occur one species generally dominates the other 
Table 3. Resource partitioning by host amongst the acanthocephalans of British freshwater fish. In this context, resource partitioning refers to the lack of coincidence of any two acanthocephalan species in both their preferred intermediate and definitive hosts. Irish host-parasite combinations are omitted for clarity and because those which differ from those shown are thought to have arisen as a result of human intervention. Acanthocephalan species in Tables 3-5 are as given in Table 1.

\begin{tabular}{|l|c|c|c|c|c|}
\hline \multirow{2}{*}{ Intermediate host } & \multicolumn{5}{|c|}{ Definitive host (preferred) } \\
\cline { 2 - 6 } & $\begin{array}{c}\text { Brown } \\
\text { trout }\end{array}$ & Eel & Perch & Chub & $\begin{array}{c}\text { Three-spined } \\
\text { stickleback }\end{array}$ \\
\hline Asellus aquaticus & & & A. lucii & A. anguillae & \\
\hline Asellus meridianus & & A. clavula & & & \\
\hline Gammarus pulex & E. truttae & & & P. laevis & \\
\hline Ostracoda & & & & & N. rutili \\
\hline Sialis lutaria & N. rutili & & & & \\
\hline
\end{tabular}

Table 4. Mean abundance (and prevalence, \%) of acanthocephalans in eels in localities sampled on more than one occasion but at irregular intervals. $\mathrm{n}$ - number of eels examined.

\begin{tabular}{|c|c|c|c|c|c|c|c|}
\hline Localities & $\mathrm{n}$ & Year & A. lucii & A. clavula & E. truttae & P. laevis & N. rutili \\
\hline R. Teifi & $\begin{array}{l}20 \\
25\end{array}$ & $\begin{array}{l}1964 \\
1988\end{array}$ & & & & & $\begin{array}{c}6.7(28) \\
0\end{array}$ \\
\hline R. Frome & $\begin{array}{l}10 \\
21\end{array}$ & $\begin{array}{l}1987 \\
1992\end{array}$ & $\begin{array}{c}101.1(40) \\
0\end{array}$ & & $\begin{array}{c}0 \\
1.7(52)\end{array}$ & $\begin{array}{c}0 \\
0.05(5)\end{array}$ & \\
\hline Shobrooke Lake & $\begin{array}{c}55 \\
131 \\
50 \\
\end{array}$ & $\begin{array}{l}1986 \\
1987 \\
1996\end{array}$ & $\begin{array}{c}0.08(40) \\
0 \\
0\end{array}$ & $\begin{array}{c}0 \\
0.16(4) \\
0\end{array}$ & & & \\
\hline R. Culm & $\begin{array}{l}20 \\
25 \\
32\end{array}$ & $\begin{array}{l}1981 \\
1986 \\
1997\end{array}$ & $\begin{array}{c}0 \\
0.16(8) \\
0\end{array}$ & $\begin{array}{c}0 \\
0 \\
0.47(31)\end{array}$ & & $\begin{array}{c}0 \\
0 \\
10.9(62)\end{array}$ & \\
\hline Exminster Marshes & $\begin{array}{l}12 \\
20 \\
64 \\
22\end{array}$ & $\begin{array}{l}1981 \\
1986 \\
1987 \\
1993\end{array}$ & & $\begin{array}{l}0.87(8) \\
4.5(80) \\
3.6(78) \\
2.1(55)\end{array}$ & & & $\begin{array}{c}0 \\
0 \\
2.7(40) \\
0\end{array}$ \\
\hline Hampshire Avon & $\begin{array}{l}14 \\
22 \\
24 \\
18\end{array}$ & $\begin{array}{l}1968 \\
1980 \\
1987 \\
1993\end{array}$ & & & & $\begin{array}{c}2.0(25) \\
10.7(100) \\
8.7(67) \\
8.6(94)\end{array}$ & \\
\hline
\end{tabular}

Table 5. Long-term changes in the mean abundance (maximum and minimum) of acanthocephalans in eels from four localities sampled regularly over periods of at least 13 years. NS - no samples taken.

\begin{tabular}{|c|c|c|c|c|c|c|c|c|c|}
\hline \multirow{3}{*}{ Year } & \multirow{2}{*}{\multicolumn{2}{|c|}{ R. Clyst }} & \multirow{2}{*}{\multicolumn{3}{|c|}{ R. Otter }} & Slapt & Ley & \multirow{2}{*}{\multicolumn{2}{|c|}{ L. Derg }} \\
\hline & & & & & & Perch & Eel & & \\
\hline & A. clavula & N. rutili & A. clavula & N. rutili & P. laevis & \multicolumn{2}{|c|}{ A. clavula } & A. lucii & A. anguillae \\
\hline 1979 & $1.7-2.5$ & & & & & 1.9 & NS & & \\
\hline 1980 & $0.2-1.9$ & & & & & 0.1 & NS & & \\
\hline 1981 & $0.05-0.5$ & & & & & 0 & NS & & \\
\hline 1982 & $0-1.1$ & & & & & NS & NS & & \\
\hline 1983 & $0-0.04$ & & & & & 0 & NS & $5.6-68$ & $0.1-0.5$ \\
\hline 1984 & 0 & & & & & 0 & NS & $5.2-78.3$ & $0.1-1.0$ \\
\hline 1985 & NS & NS & 0 & 0 & 0 & 0 & 0.5 & $5.4-62$ & $00.08-0.25$ \\
\hline 1986 & NS & NS & 0 & 0.03 & 0 & 0 & 9.7 & $1.5-76.0$ & $0-0.3$ \\
\hline 1987 & $0-0.03$ & $0-0.06$ & 0.03 & 0 & 0 & 0 & 5.5 & $16.7-50.5$ & $0.2-0.6$ \\
\hline 1988 & NS & NS & 0 & 0 & 0 & NS & NS & $0.2-54.7$ & $0.2-0.9$ \\
\hline 1989 & NS & NS & 0 & 0 & 0 & NS & NS & $2.8-26.4$ & $0.1-0.6$ \\
\hline 1990 & NS & NS & NS & NS & NS & NS & NS & $22.8-56.8$ & $0.2-0.6$ \\
\hline 1991 & $0.03-0.1$ & $0-0.03$ & 0.06 & 0 & 0.25 & 0 & NS & $11.5-29.7$ & $0.1-0.2$ \\
\hline 1992 & $0-0.03$ & $0.2-0.5$ & NS & NS & NS & 0 & NS & $5.9-13.5$ & $0-0.07$ \\
\hline 1993 & NS & NS & NS & NS & NS & 0 & NS & $4.4-13.6$ & $0-0.3$ \\
\hline 1994 & 0.47 & 0 & 0 & 0 & 0.3 & 0 & NS & $2.2-9.4$ & $0.04-0.1$ \\
\hline 1995 & $0-0.1$ & $0.1-1.2$ & 0 & 0.14 & $0.05-1.3$ & 0 & 0.01 & $4.6-24.6$ & $0.06-0.5$ \\
\hline 1996 & NS & NS & 0 & 0 & $00.2-1.5$ & 0 & 0 & $2.0-14.5$ & $0.2-0.4$ \\
\hline 1997 & NS & NS & 0 & 0 & 0.2 & 0 & 0 & $0.7-61.4$ & $0-0.04$ \\
\hline \multicolumn{2}{|c|}{$\begin{array}{l}1997 \text { NS } \\
\text { Total no. samples }\end{array}$} & 45 & \multicolumn{3}{|c|}{27} & \multicolumn{2}{|c|}{36} & \multicolumn{2}{|c|}{67} \\
\hline
\end{tabular}


(Kennedy 1985, Kennedy et al. 1991, Dorucu et al. 1995 ) in a manner that is consistent with competition. Competition is also likely to occur when two species cooccur in the same suitable, but not preferred, host, for example in England, when $A$. anguillae and $A$. lucii utilise eels (Kennedy 1992), or in Ireland, where $A$. anguillae uses eels as its preferred host (in the absence of chub) and frequently encounters $A$. lucii which uses eels as an additional/suitable host (Kennedy and Moriarty 1987, Kennedy 1992). It can also be predicted that the probability of competition between $E$. truttae and $P$. laevis will be high in Ireland, where the introduced $P$. laevis uses brown trout as its preferred host in the absence of chub. Since both species also use the same intermediate host, they uniquely show identical host utilisation. If $P$. laevis is the superior competitor (something which remains to be demonstrated), this may explain why it is the more widespread and commoner species in Ireland (Holland and Kennedy 1997), whereas E. truttae is common only in isolated catchments such as Lough Inchiquinn in the Fergus system (unpublished data) from which $P$. laevis is absent (Kane 1966). Thus, interspecific competition is likely to be more common in Ireland as species are forced into sharing definitive hosts in the absence of their preferred definitive hosts from that country (Griffiths 1997).

The ability of each species of acanthocephalan to use other hosts may thus occasionally bring species into competition and influence their distributions (Kennedy et al. 1989) but it is crucial to the colonisation and survival strategy of each species. The ability of every species to use at least one species of migratory fish as a preferred or suitable host allows the parasite to escape the confines of a catchment when migratory fish stray into neighbouring rivers via the sea or, in the case of eels, occasionally across land barriers. It may be significant in this context that $A$. anguillae is the only species that does not appear to be able to use brown trout as a preferred or suitable host and this species shows the most localised distribution of any acanthocephalan species in Britain (Kennedy et al. 1989) and has a very focal distribution in the River Shannon system in Ireland (Holland and Kennedy 1997). The ability of an acanthocephalan species to use a fish such as brown trout as a 'colonisation' host will give the parasite considerable potential and ability to overcome natural barriers to dispersal.

Invasion of a new locality by a parasite in a colonisation host could, of course, precede the arrival of the preferred host, in which case the parasite may survive in the colonisation host until the preferred host does arrive - if ever. For example, P. laevis was introduced to the River Otter with brown trout and has survived several years in the absence of chub (Kennedy 1996). The status of $A$. anguillae and $P$. laevis in Ireland can be interpreted in this same light: both were introduced to Ireland by a colonisation host, albeit by anthropochore stocking, and survive in eels and brown trout respectively (Kennedy et al. 1989) pending the arrival or introduction of chub (or barbel). In the time since introduction, $P$. laevis at least has evolved sufficient distinct characteristics to be considered a separate strain. It is also possible that the marine strain of $P$. laevis, which uses flounders (Pleuronectes flesus L.) as a preferred definitive host (Kennedy 1984a, Munro et al. 1989) arose in a similar manner, from the initial use of flounders as a colonisation host by a freshwater strain and the subsequent adaptation of the parasite to this host under marine conditions.

The ability of the acanthocephalans to use several species of fish as suitable hosts and/or colonisation hosts will also assist the survivorship of a species in a locality if the preferred host population declines or disappears for any reason. The parasite can survive in the alternative host until either the preferred host returns or its population recovers. For example, the presence of E. truttae in eels in parts of the River Trent system in eastern England and indeed its persistence in parts of that system in that host may be an example of its survival in a colonisation host in the absence of its preferred host (brown trout) due to pollution. Colonisation hosts may similarly provide a rescue effect by continually re-introducing parasites into a declining population, as appears to have happened in the River Clyst where the population of $A$. clavula in eels was maintained by an influx of infected eels from the River Exe (Kennedy 1984b), although in this case, eels are also the preferred host. The erratic and irregular appearance of acanthocephalans in several localities over time (Table 4) may in some cases reflect survival in alternative host species, whereas in others it probably arises from irregular movements of colonisation hosts into the locality. There is evidence that colonisation of localities by acanthocephalan species is a relatively frequent event e.g. N. rutili in the R. Clyst and R. Otter for which eels are the only host, and P. laevis in the R. Otter. In practice it matters little whether the introduction of the colonisation host is natural or a consequence of anthropochore activity: the final result is the same, in that a species may be introduced or saved from the edge of local extinction by a rescue effect. It is also clear that local extinction does occur (as in the R. Clyst and Slapton Ley) and that species can persist for long periods at low abundance levels e.g. A. anguillae in L. Derg, even if no colonisations or extinctions are taking place.

Although acanthocephalans are considered to be very specific to their intermediate hosts, they may be more adaptable than is generally believed and it is probable that some species have changed their intermediate host over evolutionary and historic time. It is believed that the first freshwater fish to colonise the British Isles post-glacially were the migratory, euryhaline salmonids 


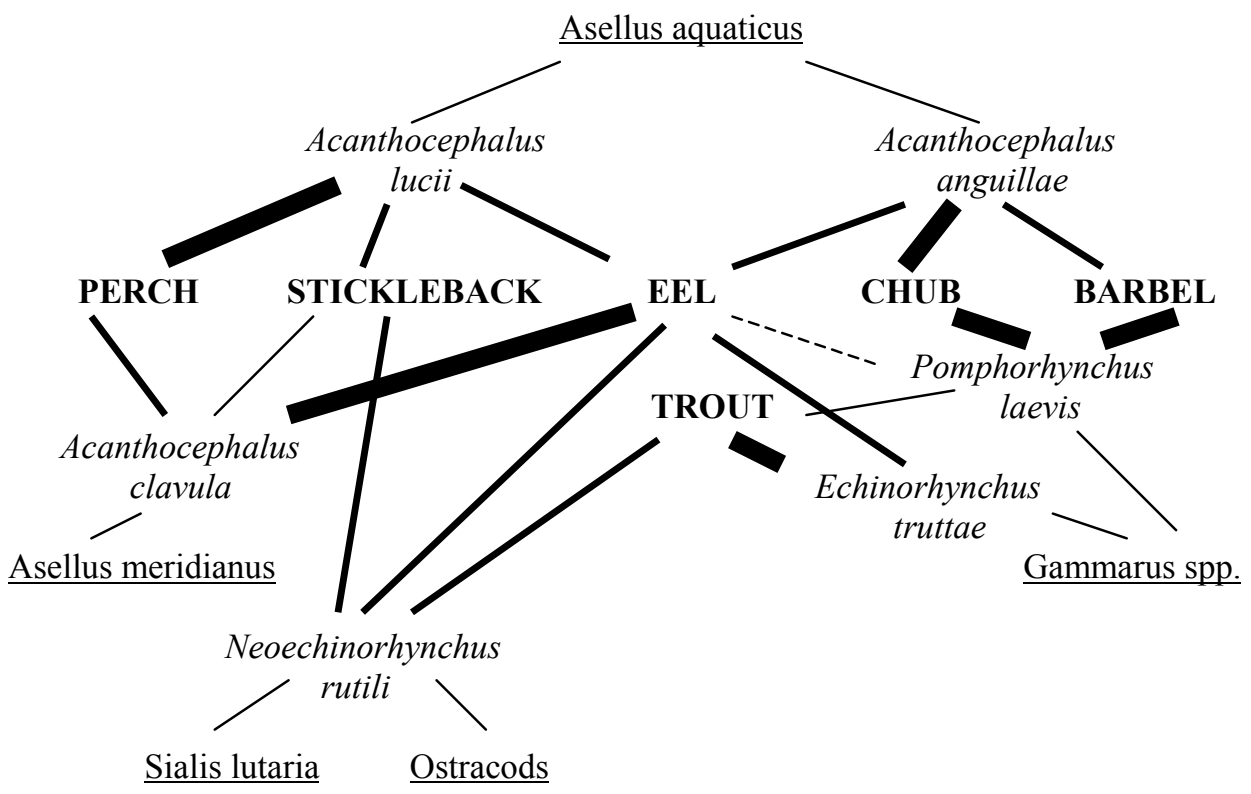

Fig. 1. A schematic diagram of the inter-relationships between the six species of acanthocephalan infecting British freshwater fishes (italics) and their intermediate (underlined) and definitive (capitals) hosts. Thicknesses of lines joining the parasites to definitive hosts indicate the relative importance of those hosts. Host-parasite relationships in Ireland have been omitted for clarity.

and eels (Varley 1967, Wheeler 1977). It is therefore probable that the first species of acanthocephalans to reach the British Isles post-glacially were those that use these fish as their preferred definitive hosts and for which the preferred host is also, therefore, a colonisation host. Echinorhynchus truttae falls into this category, but it must initially have used an intermediate host other than Gammarus pulex, possibly G. duebeni, since G. pulex was a later invader of Britain (Gledhill et al. 1993). In Ireland, it is suggested that E. truttae has continued to use $G$. duebeni as its intermediate host, but in Britain it has switched to using G. pulex. In contrast, A. clavula has continued to use Asellus meridianus Racovitza as its intermediate host in both Britain and Ireland, although this isopod has been displaced by the later colonist $A$. aquaticus in many parts of Britain. There is no evidence that $A$. clavula is in the process of switching intermediate host in Britain, but in Italy this acanthocephalan has been recorded from Echinogammarus pungens Edwards (Dezfuli et al. 1991a), which may represent a host switch.

The later arrival in the British Isles of stenohaline, freshwater cyprinid fish probably brought with them $P$. laevis and A. anguillae. For these species, the preferred host is not a colonisation host, and they use salmonids and eels for dispersal and colonisation. It is, of course, possible that the arrival of these parasites in some parts of Britain was via such colonisation hosts, and preceded that of their preferred definitive host species. Acanthocephalus anguillae could probably have used its normal intermediate host, A. aquaticus, which was likely present at least in the south-east of the British Isles several thousand years ago (Williams 1963). In freshwater, $P$. laevis could use G. pulex in Britain, but when introduced to Ireland, by anthropochore means (Kennedy et al. 1989), it had perforce to change host to G. duebeni (Fitzgerald and Mulcahy 1983). In the course of its evolution the marine strain has also had to change intermediate host to G. zaddachi and G. locusta (Lundstrom 1942, Munro et al. 1989, Strong and Lyndon unpublished data). The wider distribution of $A$. lucii in the British Isles may reflect the earlier arrival and wider distribution of perch (Varley 1967). The situation regarding $N$. rutili and its history in the British Isles is still unclear. It may have been an early arrival using the salmonids as preferred and colonisation hosts, or it may be more recent. Its use of two different lifecycle pathways is unique amongst the acanthocephalans and this clearly gives it additional colonisation and survival potential, perhaps explaining why it is the only one of the species considered with a Holarctic distribution.

Although this interpretation of acanthocephalan colonisation strategies has been developed with respect to freshwaters in the British Isles, all the characteristics discussed can be exemplified from other parts of the world. Pomphorhynchus laevis, for instance, uses different species of Gammarus as intermediate host in different parts of Europe, having been reported from $G$. fossarum Koch in France (van Maren 1979a) and Echinogammarus stammeri Karaman in Italy (Dezfuli et al 1991b). Similarly, E. truttae has been recorded using 
E. pungens in Italy and $G$. fossarum and E. berilloni (Catta) in France (van Maren 1979b). In Italy, A. clavula is able to utilise Asellus coxalis Dollfus, E. stammeri and E. pungens as intermediate hosts instead of $A$. meridianus (Amante et al. 1967, Dezfuli et al 1991a, 1999), whereas $A$. lucii and A. anguillae still appear to use A. aquaticus on the continent (van Maren 1979b, Dezfuli et al. 1994). In North America, Pomphorhynchus bulbocolli (Linkins) also uses one of the most common and widespread amphipods, in this case Hyalella azteca (Saussure), as its intermediate host, but it has also switched to Gammarus pseudolimnaeus Bousfield in some regions (Gleason 1987). Its preferred definitive host is probably a species of Catostomus, but it can use species of salmonids and Anguilla rostrata Le Sueur as colonisation hosts (Arai 1989). Again in North America, Echinorhynchus salmonis (Müller) uses Pontoporeia affinis Lindstrom, another widespread and common species, as its intermediate host and salmonids as its preferred and colonisation hosts (Arai 1989). A further parallel with $E$. truttae is the ability of $E$. salmonis to infect the American eel (Marcogliese and Cone 1996). In the North American part of its range, $N$. rutili can use both salmonids and three-spined sticklebacks as preferred and colonisation hosts, as well as a wide variety of other species (Arai 1989). It is not known whether in North America it can use the two different life-cycle pathways seen in the British Isles, although in Italy only the ostracod-stickleback cycle has been reported to date (Dezfuli 1996). The formation of a strain of $P$. laevis in Ireland parallels the evolution of the endemic species $P$. bosniensis in Europe, just as the European marine strain is paralleled by the more marine tolerant $P$. rocci Cordonnier et Ward in North America (Cordonnier and Ward 1967).

It is therefore evident that acanthocephalans of freshwater fish have a number of adaptations that simultaneously assist both their colonisation and survivorship abilities. Chief amongst these is their specificity. In addition to their preferred definitive host, each species can also use at least one species of migratory fish as a colonisation host, to improve their dispersal abilities and in which to survive if the preferred host declines or is absent from a locality. All species use a widespread and common arthropod as an intermediate host, although the apparently narrower specificity to this host may be more perceived than real, as several species appear to have switched their intermediate host in space, albeit over prolonged (evolutionary?) times. Nevertheless, it is suggested that resource partitioning by host minimises the probability of interspecific competition, which can occur in fish (Bates and Kennedy 1990) or arthropods (Lyndon unpublished observation), and this in turn facilitates colonisation. Mechanisms which could contribute to the maintenance of segregation in particular preferred fish hosts are discussed in more detail by Lyndon (1996).

In conclusion, the evidence presented above supports the contention that autogenic species with an indirect life cycle can, in fact, overcome the limitations supposedly associated with this life-style. Helminths from other phyla, with apparently similar limitations but with comparable adaptations have been amongst the most successful introductions and colonisers of the British Isles in recent years, as evidenced by, for example, Anguillicola crassus Kuwahara, Nimi et Itagaki, Sanguinicola inermis Plehn and Khawia sinensis Hsu (Kennedy 1993, 1994, Yeomans et al 1997). The only autogenic species with direct life cycles to have spread as widely and rapidly are Pseudodactylogyrus spp. on eels and Gyrodactylus salaris Malmberg on salmonids, which might indicate that the choice of host, i.e. a migratory fish which serves as both colonisation and preferred host, is possibly more important to a parasite colonist than the number of hosts in its life cycle.

In light of the foregoing evidence, we suggest that both of the paradigms outlined initially, namely, that allogenic species and species with direct life cycles are predicted to be better colonisers, should be abandoned.

Acknowledgements. Thanks are due to Phil and Jan Shears for fish sampling and laboratory expertise. The authors would also like to thank Dr. Sean Ashworth, Jonathan Wood, Dr. Andy Walker and Alastair Thorne for assistance in obtaining samples. This work was supported by the University of Exeter, the Natural Environment Research Council (grant GR3/8049), Heriot-Watt University and the Salmon and Trout Association Charitable Trust.

\section{REFERENCES}

AMANTE L.C., FRESI E., LANERI U. 1967: Dati preliminari sul rapporto-sessi di un Acanthocefalo parassita di Asellus (Proasellus) coxalis Dollfus (Crustacea, Isopoda). Ric. Sci. 37: 446-451.

ARAI H.P. 1989: Acanthocephala. In: L. Margolis and Z. Kabata (Eds.), Guide to the Parasites of Fishes of Canada. Part III. Can. Spec. Publ. Fish. Aquat. Sci. 107: 1-90.

BATES R.M., KENNEDY C.R. 1990: Interactions between the acanthocephalans Pomphorhynchus laevis and Acanthocephalus anguillae in rainbow trout: testing an exclusion hypothesis. Parasitology 100: 435-444.
BATES R.M., KENNEDY C.R. 1991: Potential interactions between Acanthocephalus anguillae and Pomphorhynchus laevis in their natural hosts chub, Leucisus cephalus and the European eel, Anguilla anguilla. Parasitology 102: 289-297.

BROWN A.F., CHUBB J.C., VELTKAMP C.J. 1986: A key to the species of Acanthocephala parasitic in British freshwater fishes. J. Fish Biol. 28: 327-334.

BUSH A.O., LAFFERTY K.D., LOTZ J.M., SHOSTAK A.W. 1997: Parasitology meets ecology on its own terms: Margolis et al. revisited. J. Parasitol. 83: 575-583. 
CHUBB J.C. 1967: Host specificity of some acanthocephalans of freshwater fishes. Helminthologia 8: 63-70.

CORDONNIER L.M., WARD H.L. 1967: Pomphorhynchus rocci sp. n. (Acanthocephala) from the rock bass Roccus saxatilis. J. Parasitol. 53: 1295-1297.

DEZFULI B.S. 1996: Cypria reptans (Crustacea: Ostracoda) as an intermediate host of Neoechinorhynchus rutili (Acanthocephala: Eoacanthocephala) in Italy. J. Parasitol. 82: 503-505.

DEZFULI B.S., ROSSETTI E., BELLETTATO C.M., MAYNARD B.J. 1999: Pomphorhynchus laevis in its intermediate host Echinogammarus stammeri in the River Brenta, Italy. J. Helminthol. 73: 95-102.

DEZFULI B.S., ROSETTI E., FANO E.A., ROSSI R. 1994: Occurrence of larval Acanthocephalus anguillae (Acanthocephala) in the Asellus aquaticus (Crustacea, Isopoda) from the River Brenta. Boll. Zool. 61: 77-81.

DEZFULI B.S., ROSSETTI E., ZANINI N., ROSSI R. 1991a: Occurrence of Acanthocephalus clavula (Acanthocephala) in Echinogammarus pungens (Amphipoda) from the River Adige. Parassitologia 33: 121-126.

DEZFULI B.S., ZANINI N., REGGIANI G., ROSSI R. 1991b: Echinogammarus stammeri (Amphipoda) as an intermediate host for Pomphorhynchus laevis (Acanthocephala) parasite of fishes from the River Brenta. Boll. Zool. 58: 267-271.

DORUCU M., CROMPTON D.W.T., HUNTINGFORD F.A., WALTERS D.E. 1995: The ecology of endoparasitic helminth infections of brown trout (Salmo trutta) and rainbow trout (Oncorhynchus mykiss) in Scotland. Folia Parasitol. 42: 29-35.

ESCH G.W., KENNEDY C.R., BUSH A.O., AHO J.M. 1988: Patterns in helminth communities in freshwater fish in Great Britain: alternative strategies for colonization. Parasitology 96: 519-532.

FITZGERALD R.D., MULCAHY M.F. 1983: Parasites of salmon, Salmo salar L., and trout, Salmo trutta L., in the River Shournagh. Irish Fish. Inv. Series A 23:24-31.

GLEASON L.N. 1987: Population dynamics of Pomphorhynchus bulbocolli in Gammarus pseudolimnaeus. J. Parasitol. 73: 1099-1101.

GLEDHILL T., SUTCLIFFE D.W., WILLIAMS W.D. 1993: British freshwater Crustacea Malacostraca: a key with ecological notes. Freshwater Biological Association Scientific Publication 52: 1-173.

GRIFFITHS D. 1997: The status of the Irish freshwater fish fauna: a review. J. Appl. Ichthyol. 13: 9-13.

HINE P.M., KENNEDY C.R. 1974: Observations on the distribution, specificity and pathogenicity of the acanthocephalan Pomphorhynchus laevis (Müller). J. Fish Biol. 6: 521-535.

HOLLAND C., KENNEDY C.R. 1997: A checklist of parasitic helminth and crustacean species recorded in freshwater fish from Ireland. Biol. Env. Proc. R. Irish Acad. 97B: 225-243.

KANE M.B. 1966: Parasites of Irish fishes. Sci. Proc. R. Dublin Soc. B 18: 205-220.

KENNEDY C.R. 1974: A checklist of British and Irish freshwater fish parasites with notes on their distribution. J. Fish Biol. 6: 613-644.
KENNEDY C.R. 1975: Ecological Animal Parasitology. Blackwell, Oxford, $163 \mathrm{pp}$.

KENNEDY C.R. 1984a: The status of flounders, Platichthys flesus L., as hosts of the acanthocephalan Pomphorhynchus laevis (Müller) and its survival in marine conditions. J. Fish Biol. 24: 135-149.

KENNEDY C.R. 1984b: The dynamics of a declining population of the acanthocephalan Acanthocephalus clavula in eels Anguilla anguilla in a small river. J. Fish Biol. 25: 665-677.

KENNEDY C.R. 1985: Interactions of fish and parasite populations: to perpetuate or pioneer? In: D. Rollinson and R.M. Anderson (Eds.), Ecology and Genetics of HostParasite Interactions. Academic Press, London, pp. 1-20.

KENNEDY C.R. 1990: Helminth communities in freshwater fish: structured communities or stochastic assemblages? In: G.W. Esch, A.O. Bush and J.M. Aho (Eds.), Parasite Communities: Patterns and Processes. Chapman and Hall, London, pp. 131-156.

KENNEDY C.R. 1992: Field evidence for interactions between the acanthocephalans Acanthocephalus anguillae and A. lucii in eels, Anguilla anguilla. Ecol. Parasitol. 1: 122-134.

KENNEDY C.R. 1993: Introductions, spread and colonization of new localities by fish helminth and crustacean parasites in the British Isles: a perspective and appraisal. J. Fish Biol. 43: 287-301.

KENNEDY C.R. 1994: The ecology of introductions. In: A.W. Pike and J.W. Lewis (Eds.), Parasitic Diseases of Fish. Samara Publishing Ltd., Tresaith, Wales, pp. 189208.

KENNEDY C.R. 1996: Colonization and establishment of Pomphorhynchus laevis (Acanthocephala) in an isolated English river. J. Helminthol. 70: 27-31.

KENNEDY C.R. 1997: Long-term and seasonal changes in composition and richness of intestinal helminth communities in eels Anguilla anguilla of an isolated English river. Folia Parasitol. 44: 267-273.

KENNEDY C.R., BATES R.M., BROWN A.F. 1989: Discontinuous distributions of the fish acanthocephalans Pomphorhynchus laevis and Acanthocephalus anguillae in Britain and Ireland: an hypothesis. J. Fish Biol. 34:607619.

KENNEDY C.R., HARTVIGSEN R., HALVORSEN O. 1991: The importance of fish stocking in the dissemination of parasites throughout a group of reservoirs. J. Fish Biol. 38: 541-552.

KENNEDY C.R., MORIARTY C. 1987: Co-existence of congeneric species of Acanthocephala: Acanthocephalus lucii and A. anguillae in eels Anguilla anguilla in Ireland. Parasitology 95: 301-310.

KENNEDY C.R., NIE P., KASPERS J., PAULISSE J. 1992: Are eels (Anguilla anguilla L.) planktonic feeders? Evidence from parasitic communities. J. Fish Biol. 41: 567-580.

LASSIERE O.L. 1988: Host-parasite relationships between larval Sialis lutaria (Megaloptera) and Neoechinorhynchus rutili (Acanthocephala). Parasitology 97: 331-338.

LUNDSTROM A. 1942: Die Acanthocephalan Schwedens. Doctoral thesis, University of Lund, Sweden, 242 pp. 
LYNDON A.R. 1996: The role of acanthocephalan parasites in the predation of freshwater isopods by fish. In: S.P.R. Greenstreet and M.L. Tasker (Eds.), Aquatic Predators and Their Prey. Fishing News Books, Oxford, pp. 26-32.

MARCOGLIESE D.J., CONE D. 1996: On the distribution and abundance of eel parasites in Nova Scotia: influences of $\mathrm{pH}$. J. Parasitol. 82: 389-399.

MUNRO M.A., WHITFIELD P.J., DIFFLEY R. 1989: Pomphorhynchus laevis (Müller) in flounder, Platichthys flesus L., in the tidal River Thames: population structure, microhabitat utilization and reproductive status in the field and under conditions of controlled salinity. J. Fish Biol. 35:719-735.

PRICE P.W. 1980: Evolutionary Biology of Parasites. Princeton University Press, New Jersey, 237 pp.

VAN MAREN M.J. 1979a: The amphipod Gammarus fossarum Koch (Crustacea) as intermediate host for some helminth parasites, with notes on their occurrence in the final host. Bijdr. Dierk. 42: 97-110.
VAN MAREN M.J. 1979b: Structure and dynamics of the French upper Rhone ecosystems XII. An inventory of helminth fish parasites from the upper Rhone river (France). Bull. Zool. Mus. Amsterdam 6: 189-199.

VARLEY M.E. 1967: British Freshwater Fishes: Factors Affecting Their Distribution. Fishing News Books, London, $148 \mathrm{pp}$.

WALKEY M. 1967: The ecology of Neoechinorhynchus rutili (Müller). J. Parasitol. 53: 795-804.

WHEELER A. 1977: The origin and distribution of the freshwater fishes of the British Isles. J. Biogeography 4: 124

WILLIAMS W.D. 1963: The ecological relationships of isopod crustaceans Asellus aquaticus (L.) and $A$. meridianus Rac. Proc. Zool. Soc. Lond. 140: 661-679.

YEOMANS W.E., CHUBB J.C., SWEETING R.A. 1997: Khawia sinensis (Cestoda: Caryophyllidea) - an indicator of legislative failure to protect freshwater habitats in the British Isles? J. Fish Biol. 51: 880-885. 